\title{
A Process Simulation Model of Airline Passenger Check - In
}

\author{
Lamphai Trakoonsanti \\ College of Logistics and Supply Chain, Suan Sunandha Rajabhat University, Nakhonpahom Learning Center, Thailand
}

Copyright $\bigcirc 2016$ by authors, all rights reserved. Authors agree that this article remains permanently open access under the terms of the Creative Commons Attribution License 4.0 International License

\begin{abstract}
The purpose of this paper is to analyze the operation of passenger check - in desks of Nok Air at the Nakhon Si Thammarat airport, Thailand in order to simulate the operational model to improve efficiency in processes. This is because its functions describe how the objects move between the elements and model a variety of real processes. The methodology in this research is to implement the SimQuick process simulation software which helps analyze emerging needs of major objects model and determine the flow of operations, including entrances, work stations, buffers, and decision points and exits. By collecting useful data, the simulation model of how the check- in desk of the airline is operated can be accurately drawn, and conclusions as well as suggestions can be made. The approach formulated demonstrates the efficient allocation of resources and the resolution of operational issues that could prevent ultimate outcomes.
\end{abstract}

Keywords Process Flow, Process Simulation Software, Check-in Desks

\section{Introduction}

It is often the case that the time a passenger spends at the origin airport is longer than the duration of the flight due to the inefficiency check-in process. According to this, airline service plays a significant role for customers or passengers in choosing an airline. Business travelers often have high demand for opportunities to late check-in, for example, by requiring a separate check-in desk against a long line of less time-sensitive travelers. If the airline service can provide a good illustration of the differences between 'Apparent' and 'True', the business travelers could advantage the most due to the benefit of time maximization in their office before having to leave to the airport. (Shaw 2011,p.34).

Checking in does not only mean to report to the desk and get the boarding pass, but also to register or to weight bags and luggages. As at any moment, passenger may be checking in for several different flights (Lee and Longton 2014, p.56).

Moreover, the aviation industry is gradually growing. Many domestic airports show a high increase in the number of air passengers. The growth continuously encourages the provision of high quality and positive experiences for passengers at airport terminals (Joustra and Dijk 2001, p.1023). To achieve passenger's satisfaction, it is extremely necessary to be aware and understand his expectations as well as needs and preferences. It is not uncommon for an airline to hold the satisfaction of a passenger to be self-evident, or for them to believe that their relationship with a passenger allows them to exactly know the satisfaction level (Raab, Ajami, Gargeya and Goddard 2009, p.60). 
Table 1. Air traffic at Nakhon Si Thammarat Airport in year 2015

\begin{tabular}{|c|c|c|c|c|c|c|c|c|c|c|}
\hline \multirow{2}{*}{\multicolumn{2}{|c|}{ Form : BKKMONALL }} & \multicolumn{8}{|c|}{ NAKHON SI THAMMARAT AIRPORT } & \multirow{2}{*}{$\begin{array}{l}\text { Page : } 1 \\
\text { rSF }\end{array}$} \\
\hline & & Monthly & All Traffic $f$ & for the Year & xxxx From & ate : $01 / 01$ & 15 To Dat & : 31/10/201 & & \\
\hline Month & Arrival & Departure & Arrival & Departure & Transit & Unloaded & Loaded & Transfer & Unloaded & Loaded \\
\hline JANUARY & 796 & 796 & 45,855 & 50,532 & 0 & 56,508 & 26,573 & 0 & 39,481 & 14,452 \\
\hline FEBRUARY & 735 & 735 & 46,006 & 46,975 & 0 & 60,934 & 24,105 & 0 & 49,326 & 19,613 \\
\hline MARCH & 830 & 830 & 53,647 & 56,203 & 0 & 49,258 & 26,138 & 0 & 72,003 & 18,778 \\
\hline APRIL & 776 & 776 & 50,680 & 51,162 & 0 & 40,694 & 27,630 & 0 & 60,298 & 16,552 \\
\hline MAY & 811 & 808 & 50,947 & 50,143 & 0 & 30,484 & 26,352 & 0 & 69,950 & 21,415 \\
\hline JUNE & 769 & 769 & 46,213 & 46,296 & 0 & 33,393 & 23,126 & 1,223 & 58,874 & 24,708 \\
\hline JULY & 835 & 834 & 51,487 & 49,932 & 18 & 36,152 & 19,532 & 0 & 73,431 & 32,922 \\
\hline AUGUST & 815 & 819 & 52,123 & 55,279 & 0 & 32,221 & 20 & 0 & 2 & 1 \\
\hline SEPTEMBER & 785 & 785 & 48,078 & 48,654 & 0 & 33,944 & 6,510 & 0 & 94 & 8 \\
\hline OCTOBER & 842 & 842 & 60,992 & 61,180 & 0 & 78,538 & 27,659 & 0 & 39,549 & 599 \\
\hline Total & 7,994 & 7,994 & 506,028 & 516,356 & 18 & 452,126 & 207,645 & 1,223 & 463,008 & 149,048 \\
\hline
\end{tabular}

Table 2. Commercial air transport statistics classified by airline at Nakhon Si Thmmarat Airport in year 2015

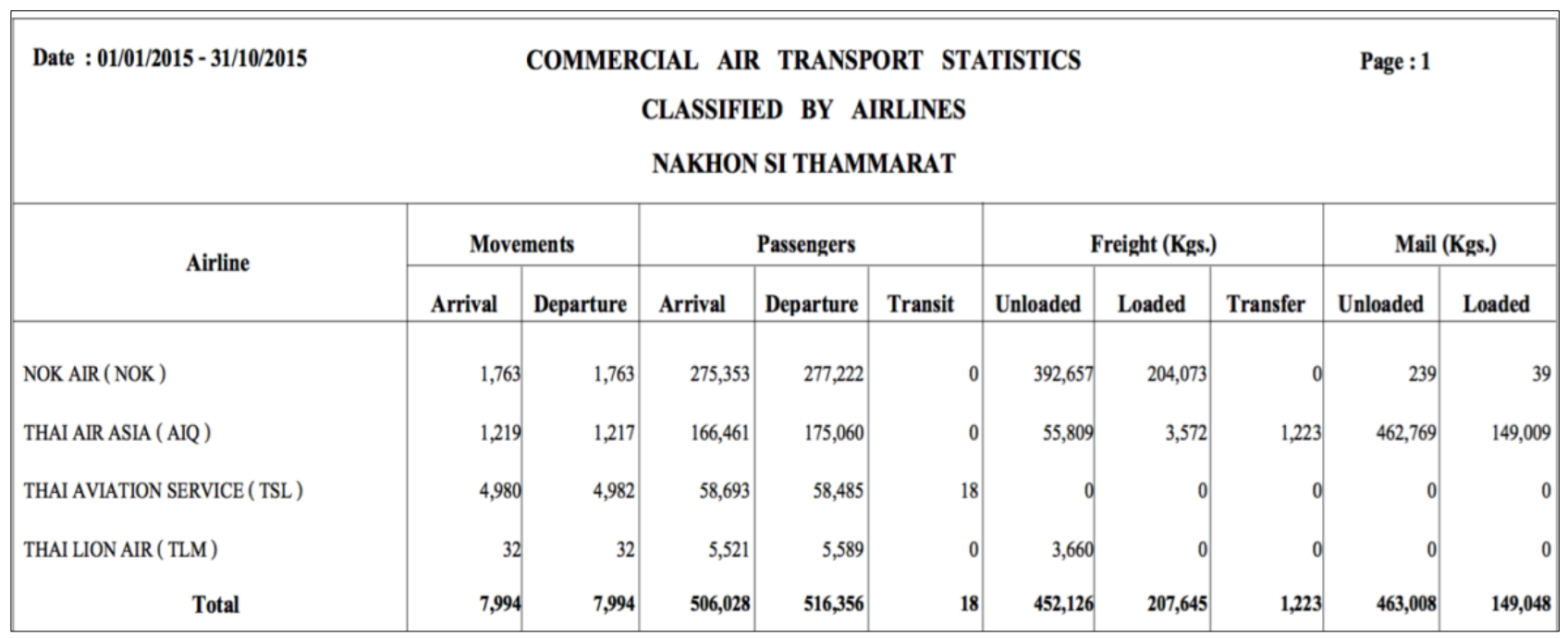

The table 1 shows that the number of aircraft movement and passengers at the Nakhon Si Thammarat airport was fluctuated, yet increasing compared to previous years. Airline service will be facing a challenging task of efficient and effective handling of the increased volume of passengers, freight, and baggages (Robinson 2010, pp.226). The airline management will need to analyze the trade-off between the cost of providing high quality service which shortens the check-in process and the cost caused from a long waiting time. For the later, managers will also need to ensure that passengers do not become unhappy and either without buying or buy but never return (Haksever and Render, 2013). Waiting in lines is a common situation, but this analysis of waiting line length, average waiting time, and other factors can help to understand the capacity of an airline's service system (Jandasang, 2015).

The table 2 demonstrates that Nok Air was the most used for commercial air transport, with which around 275,222 passengers departed and around 275,353 passengers arrived in 2015. In addition to this, air passengers still take waiting time at check-in desks into account. Passengers anticipate to the queues by arriving two or three hours before the departure of their flights (Joustra and Kijk 2001, p.1023) due to possibilities of delays occured with parking, checking in, security screening, and boarding. The less time the passenger spends in the systems, indeed, the higher the satisfaction (Guizzi, Murino, Romano, 2011, p.427). Although passengers acknowledge the need for increased security, 
delayed boarding, cancelled flights, long waiting time have created an environment of passenger dissatisfaction (Guizzi, Murino, Romano 2011, p.427). In order to investigate and improve airline operation to decrease waiting times of passenger, this paper involves understanding the check-in process flow at Nok Air check-in desks and their passengers along with collecting date and analyzing the collected data. A new, more efficient operation and process flow at the check-in desks will be suggested outlined.

\section{Literature Review}

Haksever C. and Render B. (2013) reviewed that simulation is a technique in which random numbers are used to draw inferences about probability distributions. Using this approach, many hours, days, or months of data can be developed by a computer in a few seconds. This allows analysis of controllable factors, such as adding another service channel, without actually doing so physically. Basically, whenever a standard analytical queuing model provides only a poor approximation of the actual service system, it is wise to develop a simulation model instead.

Lee A.M. and Longton P. (2013) examined that queuing processes associated with airline passenger check - in is the first thing which airline passenger must do on reporting for his flight at any report or town terminal is to check in that is register his baggage, and exchange his flight for a boarding pass. As at any moment, passengers may be checking in for several different flights, a number of manned service positions must be provided. The study describes an operational research study which was carried out to determine the best type of check - in system to adopt at certain stations.

Guizzi G., Morino T., and Romano E. (2011) studied passenger flow in the terminal airport, from entrance to boarding. In particular, this study develops a simulation model based on discrete event theory that can be used to build a structure that helps to predict delay and to produce a logical and rational management of check-in and security checkpoint inside the airport terminal. The proposed model, tested in the South Italian reality Naples International Airport, has a modular architecture and interface, enabling quick and easy model building and providing the capability of being adaptable to the configuration and operational characteristics of a wide range of airport terminals.

Fayes, et al. (2008) analyzed that airline terminal operation has changed on the area of passenger service which due to the tightened security measures. The focus of this article is to shows the methodology and the general tool that will explain passenger flow and performance which relate to level of service in airport terminal functional areas. Their research focuses on airport terminal simulation tool called AirSim. This software is a general airport simulation to analyze the current situation of the airport functional areas. The authors presented several scenarios which were built to evaluate the airport level of service.
Hartvigsen D. (2004) reviewed that simulation is particularly useful when there is uncertainty in a process (e.g., the arrival times of customers, the demand for a product, the supply of parts, the time it takes to perform the work, the quality of the work). With uncertainty, it is often difficult to predict the effects of making changes to a process, especially if there are two or more sources of uncertainty that interact and process simulation is a widely used technique for improving the efficiency of processes. Following are some examples of processes and some related efficiency problems that can be addressed with process simulation.

Raab, et all. (2009) examined that customer satisfaction is the degree of correspondence between the expectations that a potential customer has for product or service, and the perceived services that is in fact provided. If the perceived service fulfills or exceeds the standard of comparison based on, customer satisfaction arises. A service that fall short in compassion to expectations leads to dissatisfaction. Their discussed how the Kano method can be used on order to determine which product and service features are expected as part of the basic offering, and which features help to pleasantly surprise the customer, which increase customer satisfaction.

\section{Methodology and Data}

The simulation methodology that presented in this paper was implemented in process simulation software in excel spreadsheet environment called Simqucik (Hartvigsen, 2004). Conceptually build a model of the process using the building blocks then enter this conceptual model into SimQuick and test process improvement ideas on computer model. The building blocks in SimQuick are objects, elements, and statistical distributions. Objects represent passenger move in a process, elements represent check-in desk in process. There are five types of element in this paper consist of entrances: this is where passengers enter a process, buffers: this is where passenger can stand in line at check - in desk, work stations: this is where check-in desk is performed on passenger, decision points: this is where a passenger goes in one of two directions, exits: this is where objects leave a process. The third building block, statistical distributions, is discussed in the next section. When a SimQuick simulation begins, a "simulation clock" starts in the computer and runs for the designated duration of the simulation. While this clock is running, a series of events sequentially takes place. There are three types of events in SimQuick: the arrival of passenger at an entrance, the departure of passenger from an exit, and the finish of staff on passenger at a work station. Whenever an event occurs, SimQuick moves objects from element to element as much as possible. SimQuick keeps track of various statistics during the simulation which can analyze what happened when the simulation is over. However, this paper will be focused on Nok Air check-in desk at Nakhon Si Thammarat Airport which to analyses the current state and enables assessing process flow at different 
times under operational parameters and conditions. Simulation modelling will require data in order to be able to populate and run the simulation model and analyse the process flow performance. Data will be collected to sufficient depth to provide statistically valid sampling for input to the simulation model and the data have to be collected during a busy time of the year during a peak period at the terminal. At a minimum the data cover a full operational day for a sufficient number of hours before the first peak period through number of hours after the last peak period. The peak periods are selected based on normal flight arrival and departure schedules. However, it is proven that collecting data for the full week renders more accurate results and analysis. From a simulation and statistical perspective, it is more technical correct to collect over a peak period which means analysing the number of passenger, number of flight. In addition, the data were collected based on secondary research which gains information from Nakhon Si Thammarat Airport. Moreover, there is data collection process which means we will interview airport operators and subject matter experts, and collect preliminary data on airport design and layout, busiest time of the year, peak periods, and other information related to functional areas and then analyzing the data and model the data for simulation model input. The data will run simulation models for various scenarios and the output from the simulation model will be analyzed to draw conclusions for process flow efficiency.

\section{Modelling}

In this section, this paper describes the process flow structure and its behavior of Nok Air Passenger check-in and run the process simulation using Simquick. This model will be used to generate the simulation model in order to estimate and optimize the process performance. To model process structure, two types of process flow map are used. One process flow map is the current model which shows the elements are entrances, waiting line, check-in desk, decision point and exits. The second process flow map is the improved model. Moreover, this section consider waiting line processes in a typical process of this type, management is typically interested in determining the right number of servers or adjusting the time to serve customers Hence, the key performance measures of mean cycle time and service level are introduced. Then, this paper will define process flow in a simulation model, with a level of sufficient detail to make significant further information.

\subsection{Parameters Involved}

\subsubsection{Selection of Airline}

Nok Air operates a budget airline under the 'Nok Air' brand where it provides domestic point-to-point air transport by single-aisle aircraft. The company is the leading budget airline with the most domestic route coverage in Thailand.
Nok Air offers flight services covering every region all over Thailand (Nok Air annual report, 2014). However, due to the annual growth of passenger and flights, the capacity of the Nakhon Si Thammarat Airport becomes an issue which cause this paper chooses Nok Air counter check-in at Nakhon Si Thammarat Airport

(Department of Civil Aviation, 2015)

\subsubsection{Queuing System of Nok Air passenger check-in desk}

\section{- Passenger arrivals}

Passenger arrival varies during different hours of the day and during different days. Maximum numbers of customers are seen at the Airport between 08:00 am to 09:00 pm from Monday to Sunday. (Nok Air Flight Schedule, 2015)

\section{- Servers}

Currently there are only two passenger checks - in desk to server from at Nakhon Si Thammarat Airport at any given time. In other words, one passenger can be served simultaneously at any given time.

\section{- Arrival Process}

Arrival process is $80 \%$ deterministic. Ground staffs are well aware of the peak and quite hours. Sometimes when it is not busy for example in the morning flight, customers are served through a single check-in only.

\section{- Behavior of the passenger}

Passenger tends to mainly check-in operation at check -in desk where the passengers delivers the baggage and receives the boarding pass. Then, transit at the security controls in order to proceed to the terminal.

\subsubsection{Service Characteristics}

\section{- Service process}

Airline set up alternatives to the check-in desks to the web check-in and a real check-in procedure.

\section{- Number of server}

There are two check-in desks which work in parallel.

\section{- System Configuration}

Two ground staff work in parallel fed by a single passenger queue.

\subsubsection{Location}

- Nor Air Passenger Check-In at Nakhon Si Thammarat Airport

\subsubsection{Software Used}

SimQuick is software that allows performing process simulation within the Excel spreadsheet environment. There are three basic steps involved in using SimQuick.

- Conceptually build a model of the process using the building blocks of SimQuick. 
- Enter this conceptual model into SimQuick.

- Test process improvement ideas on this computer model.

\subsection{Current Process Flow Map of Nok Air Passenger Check-In (Basic model)}

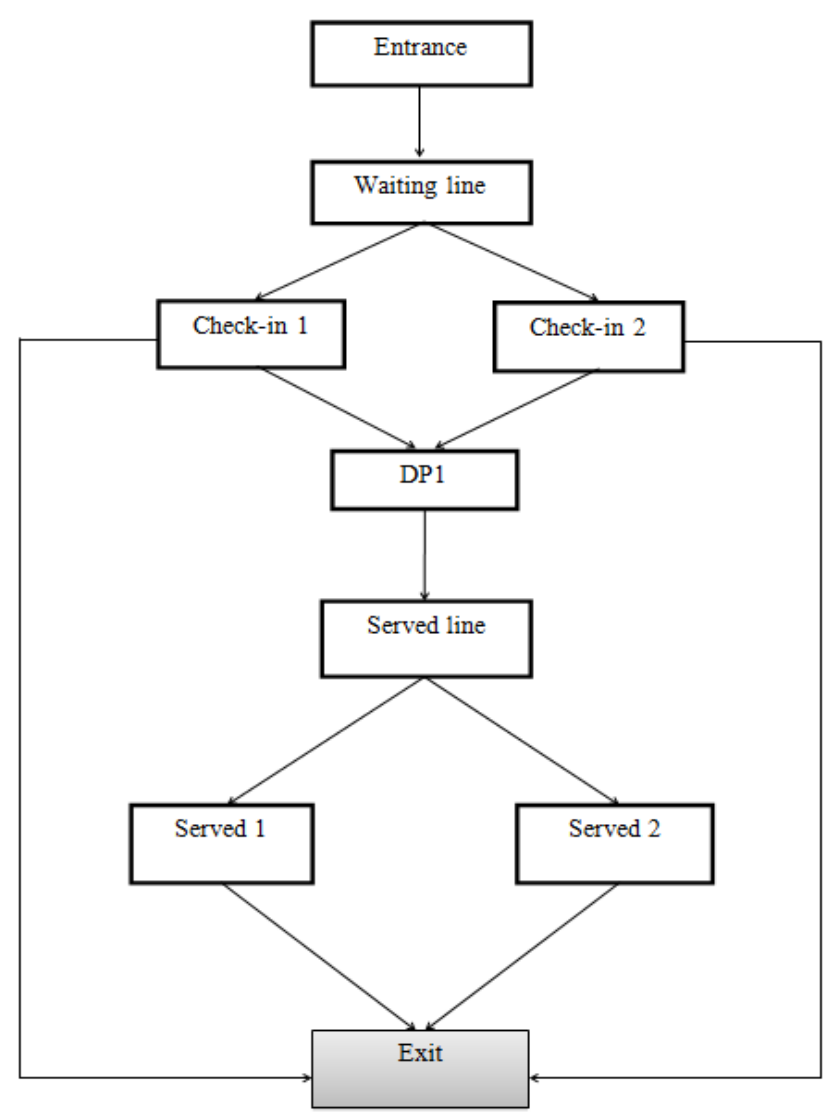

Figure 1. Flow Map of Nok Air Passenger Check-In

\subsection{Entrée in SimQuick}

This paper runs the simulation model by using collected data as an input for an Excel spreadsheet platform called SimQuick. There are three basic steps involved in using SimQuick: building blocks of objects, elements, and statistical distributions. Objects represent number of simulations that move in a process. Elements represent things that are stationary in a process. There are, however, five types of elements consisting of entrances, work stations, buffer, decision points and exits. The first type is simulation controls using time units per simulation and number of simulations. The second inputs data into entrance which consists of time between arrivals and number of objects per arrival and output destination to waiting line. The third inputs working time of check-in 1, check-in 2, served, i.e. the airline staff, 1 and served 2 as well as outputs destination to decision point 1 . The fourth inputs data in buffers using input capacity of waiting line and output to check-in 1 and check-in 2, inputs data into served line unlimitedly and outputs destination to served 1 and served 2 and go thought decision points.

\subsubsection{Basic model}

Table 3. Simulation controls

\begin{tabular}{|c|c|}
\hline Simulation controls: & \\
\hline Time units per simulation $\rightarrow$ & 120 \\
\hline Number of simulations $\rightarrow$ & 100 \\
\hline
\end{tabular}

Table 4. Entrances

\begin{tabular}{|c|c|}
\hline $\mathbf{1}$ & \\
\hline Name $\rightarrow$ & Entrance \\
\hline Time between arrivals $\rightarrow$ & Exp(1.2) \\
\hline Num. objects per arrival $\rightarrow$ & 1 \\
\hline $\begin{array}{c}\text { Output } \\
\text { destination(s) } \downarrow\end{array}$ & \\
\hline Waiting line & \\
\hline
\end{tabular}

Table 5. Work Stations

\begin{tabular}{|c|c|c|c|}
\hline & 1 & & \\
\hline & Name $\rightarrow$ & Check-in 1 & \\
\hline & $\begin{array}{l}\text { Working } \\
\text { time } \rightarrow\end{array}$ & $\operatorname{Exp}(1.27)$ & \\
\hline $\begin{array}{c}\text { Output } \\
\text { destination(s) } \downarrow\end{array}$ & $\begin{array}{c}\text { \# of output } \\
\text { objects } \downarrow\end{array}$ & $\begin{array}{l}\text { Resource } \\
\text { name(s) } \downarrow\end{array}$ & $\begin{array}{c}\text { Resource } \\
\text { \# units } \\
\text { needed } \downarrow\end{array}$ \\
\hline \multirow[t]{4}{*}{ DP1 } & 1 & Staff 1 & \\
\hline & 2 & & \\
\hline & Name $\rightarrow$ & Check-in 2 & \\
\hline & $\begin{array}{l}\text { Working } \\
\text { time } \rightarrow\end{array}$ & $\operatorname{Exp}(1.73)$ & \\
\hline $\begin{array}{c}\text { Output } \\
\text { destination(s) } \downarrow\end{array}$ & $\begin{array}{c}\text { \# of output } \\
\text { objects } \downarrow\end{array}$ & $\begin{array}{c}\text { Resource } \\
\text { name(s) } \downarrow\end{array}$ & $\begin{array}{c}\text { Resource } \\
\text { \# units } \\
\text { needed } \downarrow\end{array}$ \\
\hline \multirow[t]{4}{*}{ DP1 } & 1 & Staff 2 & 1 \\
\hline & 3 & & \\
\hline & Name $\rightarrow$ & Served 1 & \\
\hline & $\begin{array}{c}\text { Working time } \\
\qquad \rightarrow\end{array}$ & $\operatorname{Exp}(4.34)$ & \\
\hline $\begin{array}{c}\text { Output } \\
\text { destination(s) } \downarrow\end{array}$ & $\begin{array}{c}\text { \# of output } \\
\text { objects } \downarrow\end{array}$ & $\begin{array}{c}\text { Resource } \\
\text { name(s) } \downarrow\end{array}$ & $\begin{array}{c}\text { Resource } \\
\text { \# units } \\
\text { needed } \downarrow\end{array}$ \\
\hline \multirow[t]{4}{*}{ Exit } & 1 & & \\
\hline & 4 & & \\
\hline & Name $\rightarrow$ & Served 2 & \\
\hline & $\begin{array}{c}\text { Working time } \\
\rightarrow\end{array}$ & $\operatorname{Exp}(4.30)$ & \\
\hline $\begin{array}{c}\text { Output } \\
\text { destination(s) } \downarrow\end{array}$ & $\begin{array}{c}\text { \# of output } \\
\text { objects } \downarrow\end{array}$ & $\begin{array}{l}\text { Resource } \\
\text { name(s) } \downarrow\end{array}$ & $\begin{array}{l}\text { Resource } \\
\text { \# units } \\
\text { needed } \downarrow\end{array}$ \\
\hline Exit & 1 & John & 1 \\
\hline
\end{tabular}


Table 6. Buffers

\begin{tabular}{|c|c|}
\hline 1 & \\
\hline Name $\rightarrow$ & Waiting line \\
\hline Capacity $\rightarrow$ & 16 \\
\hline Initial \# objects $\rightarrow$ & 1 \\
\hline $\begin{array}{c}\text { Output } \\
\text { destination(s) } \downarrow\end{array}$ & $\begin{array}{c}\text { Output } \\
\text { group size } \downarrow\end{array}$ \\
\hline Check-in 1 & 1 \\
\hline Check-in 2 & 1 \\
\hline \multicolumn{2}{|l|}{2} \\
\hline Name $\rightarrow$ & Served line \\
\hline Capacity $\rightarrow$ & Unlimited \\
\hline Initial \# objects $\rightarrow$ & 1 \\
\hline $\begin{array}{c}\text { Output } \\
\text { destination(s) } \downarrow\end{array}$ & $\begin{array}{c}\text { Output } \\
\text { group size } \downarrow\end{array}$ \\
\hline Served 1 & 1 \\
\hline Served 2 & 1 \\
\hline \multicolumn{2}{|l|}{3} \\
\hline Name $\rightarrow$ & Exit \\
\hline Capacity $\rightarrow$ & Unlimited \\
\hline Initial \# objects $\rightarrow$ & 1 \\
\hline $\begin{array}{c}\text { Output } \\
\text { destination(s) } \downarrow \\
\end{array}$ & $\begin{array}{c}\text { Output } \\
\text { group size } \downarrow\end{array}$ \\
\hline
\end{tabular}

Table 7. Decision Points

\begin{tabular}{|c|c|}
\hline 1 & DP1 \\
\hline Name $\rightarrow$ & Percents $\downarrow$ \\
\hline Output & 45 \\
\hline destinations $\downarrow$ & 55 \\
\hline Served line & Exit \\
\hline
\end{tabular}

\subsubsection{Simulation Results}

\begin{tabular}{|c|c|c|}
\hline Element & Statistics & Overall \\
\hline names & & means \\
\hline & & 99.54 \\
\hline Entrance & Objects entering process & 0.54 \\
\hline & Objects unable to enter & 1.00 \\
\hline & Service level & NA \\
\hline & & 0.00 \\
\hline Check-in 1 & Final status & 0.00 \\
\hline & Final inventory (int. buff.) & 0.00 \\
\hline & Mean inventory (int. buff.) & 76.32 \\
\hline & Mean cycle time (int. buff.) & 0.80 \\
\hline & Work cycles started & 0.00 \\
\hline & Fraction time working & \\
\hline & Fraction time blocked & NA \\
\hline & & 0.00 \\
\hline & Final status & 0.00 \\
\hline & Final inventory (int. buff.) & 0.00 \\
\hline & Mean inventory (int. buff.) & Mean cycle time (int. buff.) \\
\hline
\end{tabular}




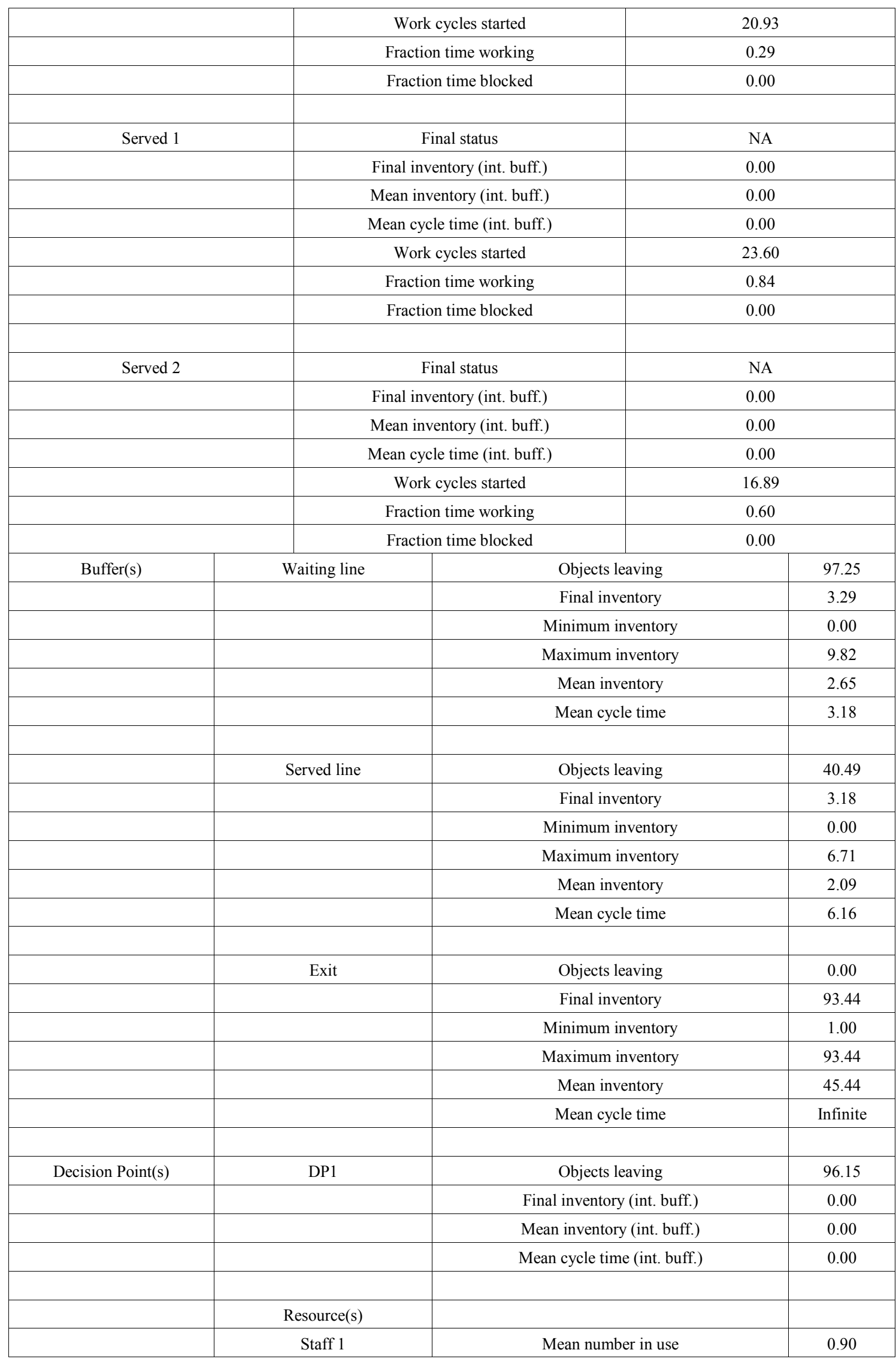




\subsection{Process Flow Map of Nok Air Passenger Check-In (Improved Model)}

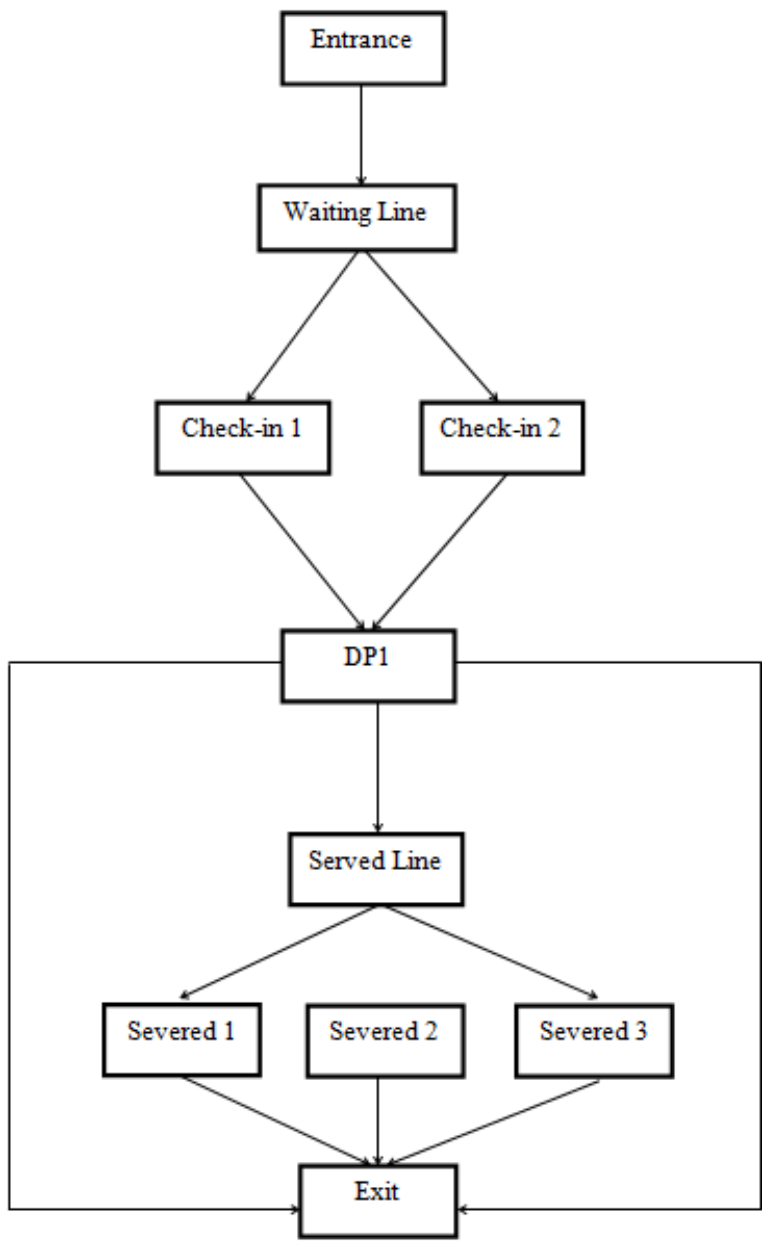

Figure 2. Improved Process Flow Map of passenger check-i

\subsection{Improved Model}

\begin{tabular}{|c|c|}
\hline Simulation controls: & \\
\hline Time units per simulation $\rightarrow$ & 120 \\
\hline Number of simulations $\rightarrow$ & 100 \\
\hline
\end{tabular}

Table 8. Entrances

\begin{tabular}{|c|c|}
\hline $\mathbf{1}$ & \\
\hline Name $\rightarrow$ & Entrance \\
\hline Time between arrivals $\rightarrow$ & Exp(1.2) \\
\hline Num. objects per arrival $\rightarrow$ & 1 \\
\hline $\begin{array}{c}\text { Output } \\
\text { destination(s) } \downarrow\end{array}$ & \\
\hline Waiting line & \\
\hline
\end{tabular}

Table 9. Work Stations

\begin{tabular}{|c|c|c|c|}
\hline & 1 & & \\
\hline & Name $\rightarrow$ & Cashier 1 & \\
\hline & $\begin{array}{c}\text { Working } \\
\text { time } \rightarrow\end{array}$ & $\operatorname{Exp}(1.27)$ & \\
\hline $\begin{array}{c}\text { Output } \\
\text { destination(s) } \downarrow\end{array}$ & $\begin{array}{c}\text { \# of output } \\
\text { objects } \downarrow\end{array}$ & $\begin{array}{l}\text { Resource } \\
\text { name(s) } \downarrow\end{array}$ & $\begin{array}{c}\text { Resource } \\
\text { \# units } \\
\text { needed } \downarrow\end{array}$ \\
\hline \multirow[t]{4}{*}{ DP1 } & 1 & & \\
\hline & 2 & & \\
\hline & Name $\rightarrow$ & Cashier 2 & \\
\hline & $\begin{array}{c}\text { Working } \\
\text { time } \rightarrow\end{array}$ & $\operatorname{Exp}(1.73)$ & \\
\hline $\begin{array}{c}\text { Output } \\
\text { destination(s) } \downarrow\end{array}$ & $\begin{array}{c}\text { \# of output } \\
\text { objects } \downarrow\end{array}$ & $\begin{array}{l}\text { Resource } \\
\text { name(s) } \downarrow\end{array}$ & $\begin{array}{c}\text { Resource } \\
\# \text { units } \\
\text { needed } \downarrow\end{array}$ \\
\hline \multirow[t]{4}{*}{ DP1 } & 1 & Staff 1 & 1 \\
\hline & 3 & & \\
\hline & Name $\rightarrow$ & Served 1 & \\
\hline & $\begin{array}{c}\text { Working } \\
\text { time } \rightarrow\end{array}$ & $\operatorname{Exp}(4.34)$ & \\
\hline \multirow[t]{4}{*}{$\begin{array}{c}\text { Output } \\
\text { destination(s) } \downarrow\end{array}$} & $\begin{array}{c}\text { \# of output } \\
\text { objects } \downarrow\end{array}$ & $\begin{array}{l}\text { Resource } \\
\text { name(s) } \downarrow\end{array}$ & $\begin{array}{c}\text { Resource } \\
\text { \# units } \\
\text { needed } \downarrow\end{array}$ \\
\hline & 4 & & \\
\hline & Name $\rightarrow$ & Served 2 & \\
\hline & $\begin{array}{c}\text { Working } \\
\text { time } \rightarrow\end{array}$ & $\operatorname{Exp}(4.30)$ & \\
\hline $\begin{array}{c}\text { Output } \\
\text { destination(s) } \downarrow\end{array}$ & $\begin{array}{c}\text { \# of output } \\
\text { objects } \downarrow\end{array}$ & $\begin{array}{l}\text { Resource } \\
\text { name(s) } \downarrow\end{array}$ & $\begin{array}{c}\text { Resource } \\
\text { \# units } \\
\text { needed } \downarrow\end{array}$ \\
\hline \multirow[t]{4}{*}{ Exit } & 1 & Staff & 1 \\
\hline & 5 & & \\
\hline & Name $\rightarrow$ & Served 3 & \\
\hline & $\begin{array}{c}\text { Working } \\
\text { time } \rightarrow\end{array}$ & $\operatorname{Exp}(4.30)$ & \\
\hline $\begin{array}{c}\text { Output } \\
\text { destination(s) } \downarrow\end{array}$ & $\begin{array}{c}\text { \# of output } \\
\text { objects } \downarrow\end{array}$ & $\begin{array}{l}\text { Resource } \\
\text { name(s) } \downarrow\end{array}$ & $\begin{array}{c}\text { Resource } \\
\text { \# units } \\
\text { needed } \downarrow\end{array}$ \\
\hline Exit & 1 & & \\
\hline
\end{tabular}


Table 10. Buffers

\begin{tabular}{|c|c|}
\hline 1 & \\
\hline Name $\rightarrow$ & Waiting line \\
\hline Capacity $\rightarrow$ & 16 \\
\hline Initial \# objects $\rightarrow$ & 1 \\
\hline $\begin{array}{c}\text { Output } \\
\text { destination(s) } \downarrow\end{array}$ & $\begin{array}{c}\text { Output } \\
\text { group size } \downarrow\end{array}$ \\
\hline Cashier 1 & 1 \\
\hline Cashier 2 & 1 \\
\hline \multicolumn{2}{|l|}{2} \\
\hline Name $\rightarrow$ & Served line \\
\hline Capacity $\rightarrow$ & Unlimited \\
\hline Initial \# objects $\rightarrow$ & 1 \\
\hline $\begin{array}{c}\text { Output } \\
\text { destination(s) } \downarrow\end{array}$ & $\begin{array}{c}\text { Output } \\
\text { group size } \downarrow\end{array}$ \\
\hline Served 1 & 1 \\
\hline Served 2 & 1 \\
\hline Served 3 & 1 \\
\hline \multicolumn{2}{|l|}{3} \\
\hline Name $\rightarrow$ & Exit \\
\hline Capacity $\rightarrow$ & Unlimited \\
\hline Initial \# objects & 1 \\
\hline $\begin{array}{c}\text { Output } \\
\text { destination(s) } \downarrow\end{array}$ & $\begin{array}{c}\text { Output } \\
\text { group size } \downarrow\end{array}$ \\
\hline
\end{tabular}

Table 11. Decision Points

\begin{tabular}{|c|c|}
\hline $\mathbf{1}$ & DP1 \\
\hline Name $\rightarrow$ & Percents $\downarrow$ \\
\hline $\begin{array}{c}\text { Output } \\
\text { destinations } \downarrow\end{array}$ & 45 \\
\hline Served line & 55 \\
\hline Exit & 45 \\
\hline
\end{tabular}

\begin{tabular}{|c|c|c|c|}
\hline Element & Element & Statistics & Overall \\
\hline types & names & & means \\
\hline \multirow[t]{3}{*}{ Entrance(s) } & Entrance & Objects entering process & 100.00 \\
\hline & & Objects unable to enter & 0.05 \\
\hline & & Service level & 1.00 \\
\hline \multirow[t]{14}{*}{ Work Station(s) } & Check-in 1 & Final status & NA \\
\hline & & Final inventory (int. buff.) & 0.00 \\
\hline & & Mean inventory (int. buff.) & 0.00 \\
\hline & & Mean cycle time (int. buff.) & 0.00 \\
\hline & & Work cycles started & 70.76 \\
\hline & & Fraction time working & 0.73 \\
\hline & & Fraction time blocked & 0.00 \\
\hline & Check-in 2 & Final status & NA \\
\hline & & Final inventory (int. buff.) & 0.00 \\
\hline & & Mean inventory (int. buff.) & 0.00 \\
\hline & & Mean cycle time (int. buff.) & 0.00 \\
\hline & & Work cycles started & 28.70 \\
\hline & & Fraction time working & 0.41 \\
\hline & & Fraction time blocked & 0.00 \\
\hline
\end{tabular}




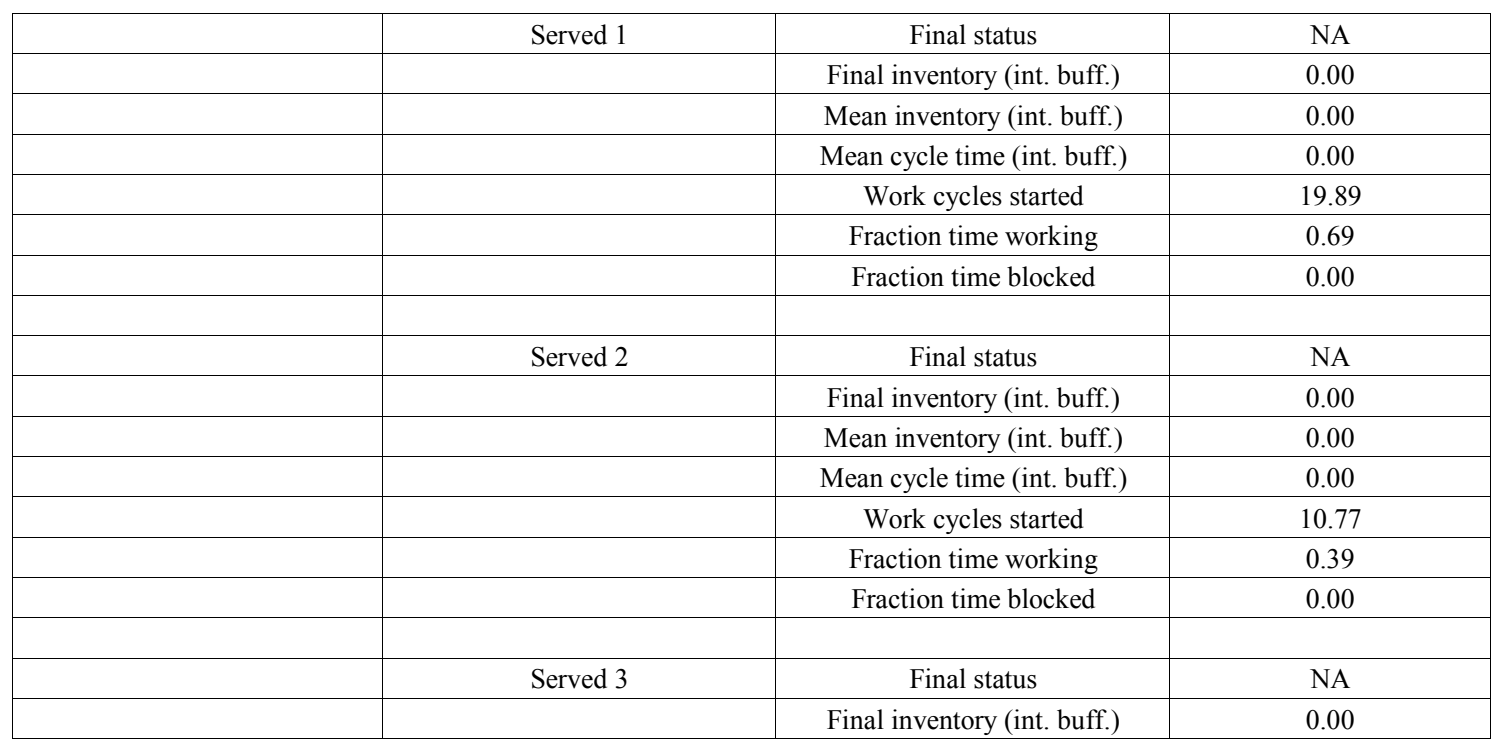

\begin{tabular}{|c|c|c|c|}
\hline & & Mean inventory (int. buff.) & 0.00 \\
\hline & & Mean cycle time (int. buff.) & 0.00 \\
\hline & & Work cycles started & 13.68 \\
\hline & & Fraction time blocked & 0.00 \\
\hline \multirow{12}{*}{ Buffer(s) } & & Minimum inventory & 0.00 \\
\hline & & Maximum inventory & 7.87 \\
\hline & & Mean inventory & 1.44 \\
\hline & & Mean cycle time & 1.70 \\
\hline & & Minimum inventory & 0.00 \\
\hline & & Maximum inventory & 3.11 \\
\hline & & Mean inventory & 0.31 \\
\hline & & Mean cycle time & 0.80 \\
\hline & Exit & Objects leaving & 0.00 \\
\hline & & Final inventory & 98.26 \\
\hline & & Minimum inventory & 1.00 \\
\hline & & Maximum inventory & 98.26 \\
\hline \multirow{6}{*}{ Decision Point(s) } & & Mean inventory (int. buff.) & 0.00 \\
\hline & & Mean cycle time (int. buff.) & 0.00 \\
\hline & & & \\
\hline & & & \\
\hline & Resource(s) & & \\
\hline & Staff & Mean number in use & 0.80 \\
\hline
\end{tabular}




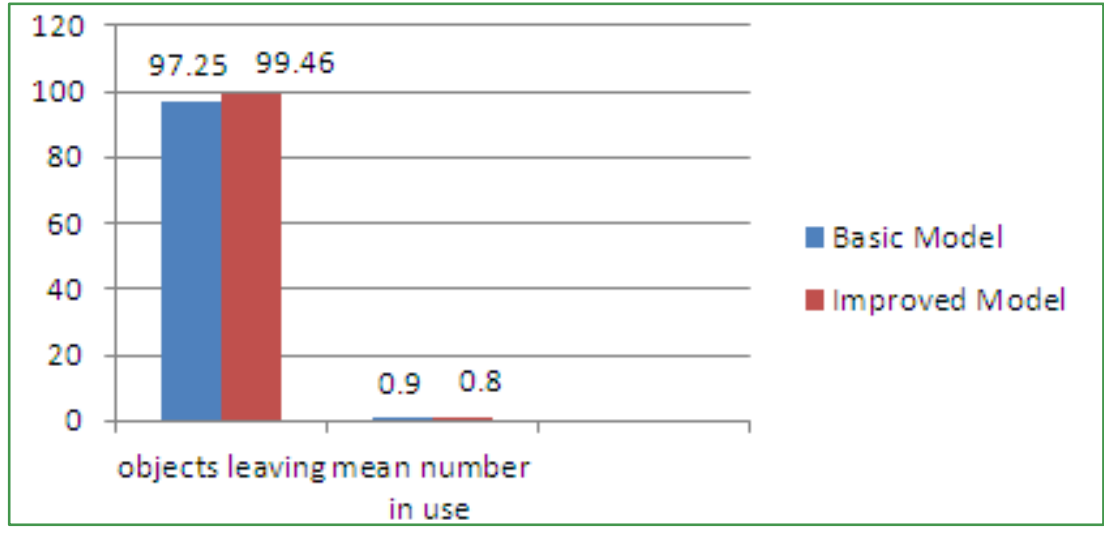

Figure 3. Compared entrance between basic model and improved model

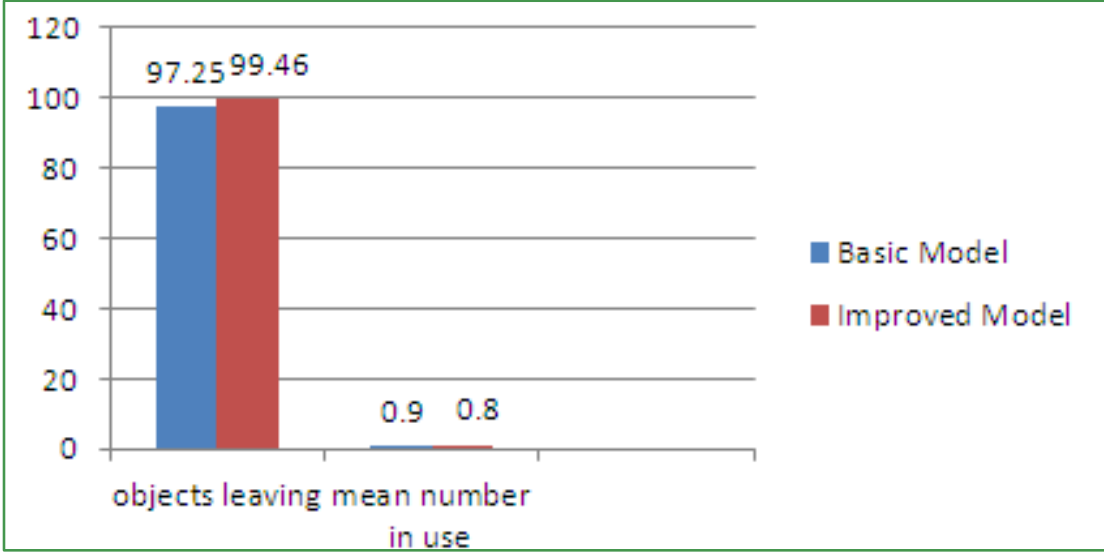

Figure 4. Comparison buffers of served line between basic model and improved model

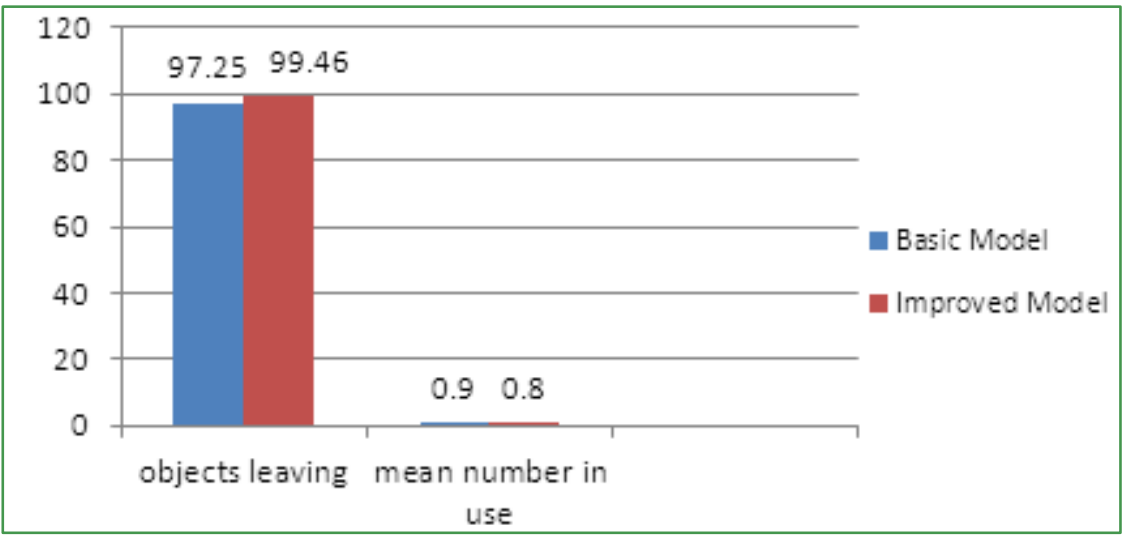

Figure 5. Comparison buffers of waiting line between basic model and improved model

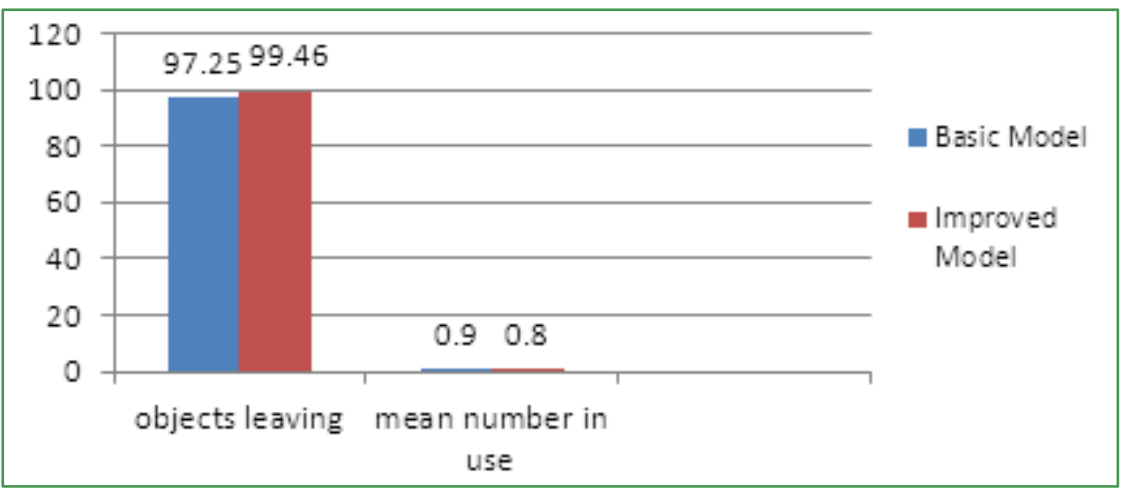

Figure 6. Comparison decisions point of basic model and improved model 


\section{Result Interpretation}

According to the basic model, $99.54 \%$ of passengers can enter to the line, and $100 \%$ of them can be served. Moreover, the efficiency between the two check-in points can be obviously observed and compared. Check-in point 1 and 2 are differently busy around $80 \%$ and $21 \%$ of the time respectively, while an airline staff who serves passengers at the check-in point 1 works up to $84 \%$ of the time but the other staff at the check-in point 2 works approximately only $64 \%$. staff is busy around $90 \%$ of the time. The total time that each passenger should spend for waiting in line is estimated to 9.34 minutes which should be essentially shortened.

On the other hand according to the improved model, the third airline staff can serve passengers more efficiently through less waiting time and increased customer satisfaction. Based on this model, $100 \%$ of the passengers can and be served. Check-in point 1 and 2 are busy around $73 \%$ and $41 \%$ of the time respectively. The first at the check-in point 1 work $69 \%$ of the time the second staff at the check-in point 2 around $39 \%$, and $48 \%$ for the third staff. In general, the airline ground staff is busy around $80 \%$ of the time. The total average time that each passenger spends in line is decreased by 6.84 minutes meaning that a passenger only spend 2.5 minutes to check-in.

\section{Conclusions}

The process simulation model and the process flow of passenger checking-in were examined and developed. Queuing theory and simulation are useful in the airline industry as they provide helpful information about the required capacity so that passengers are not forced to wait an unreasonable length of time. The excel spreadsheet with simulating complex tasks is almost a necessity to valid conclusions from a simulation. It can generate random numbers, simulate thousands of time periods in a matter of seconds or minutes, and provide management with reports which help making decision easier and approachable. Nevertheless, the queuing model greatly helps the airline make decisions that balance desirable capacity costs with waiting-line costs. Some of many measure the performance of a waiting-line system that is commonly obtained in a queuing analysis. The results points that if the number of check-in desks is increased to at least 3 check-in desks, the queue will indeed become shorter than just offering but a passenger still requires a long time until the whole check-in process in done. In contrary, if the amount of employees at work stations are increased, the waiting line is to be as long, however, the time of process between the start of checking-in and the end of receiving the boarding pass is dramatically decreased. Hence, it is much better to employ at least one employee more to decrease the process flow time of checking-in at the airline counters, including waiting in line.

\section{REFERENCES}

[1] Abdelghany, K., Abdelghany, A. \& Narasimhan, R. 2006, "Scheduling baggage-handling facilities in congested airports", Journal of Air Transport Management, vol. 12, no. 2, pp. 76-81.

[2] Ahyudanari E., Vandeboma U., "Simplified model for estimation of airport check - in facilities", Journal of the Eastern Asia Society For Transportation Studies, Vol. 6, pp. $724-735,2005$.

[3] Appelt S., Batta R., Lin Li, Drury C., (2007). "Simulation of passenger check-in at a medium sized airport", Proceedings of the 2007 Winter Simulation Conference, 1252-1260.

[4] Fayez, M.S., Kaylani, A., Cope, D., Rychlik, N. \& Mollaghasemi, M. 2008, "Managing airport operations using simulation", Journal of Simulation, vol. 2, no. 1, pp. 41-52

[5] Gatersleben M. and Weij S. (2013), “Analysis and Simulation Of Passenger Flows In An Airport Terminal”, Proceeding Of The 1999 Winter Simulation Conference, pp.1126-1230.

[6] Guizzi G., Murino T., Romano E. (2013) "A Discrete Event Simulation To Model Passenger Flow In The Airport Terminal", The Journal of Mathematical Methods and Applied Computing, pp.427-434.

[7] Haksever C. and Render B. (2013), Service Management, United State of America, Pearson Education, Inc.

[8] James T., Huang E., Shih P., and Chiu C. (2015) "Airport Baggage Handling System Simulation Modeling Using SysML", Proceeding of the 2015 International Conference on Industrial Engineering and Operation Management.

[9] Jandasang Duangjai. (2015) "Factors Affective The Service Of Transportation Use Of Outbound Freight Case Study Of Operators". Ph.D. in Social Science Journal (5)3. 52-67.

[10] Jousta, p., and Van Dijk, N., 2001. "Simulation of Check - in at Airports", Proceeding of the 2001 Winter Simulation Conference, 1023.

[11] Lee A.M. and Longton P.A. (2011), "Queuing Process Associated With Airline Passenger Check-In”, pp.56 - 71.

[12] Raab G., Ajami R., Gargeya V., and Goodard G., (2009), Customer Relationship Management, England, Gower Publishing Limited. 